\title{
A configuração da educação do campo em dois assentamentos rurais em Mato Grosso
}

The configuration of current rural education in two rural settlements in Mato Grosso

\author{
Heloisa Salles Gentil* \\ Universidade do Estado de Mato Grosso \\ Ilma Ferreira Machado** \\ Universidade do Estado de Mato Grosso
}

Resumo Este texto apresenta a análise da constituição da educação do campo em assentamentos rurais, a partir de um projeto de extensão, em interface com pesquisa, que buscou identificar ações e desafios, concepções e perspectivas em relação à educação, colocados para os sujeitos do campo, explicitando a interconexão entre um projeto educativo e um projeto de desenvolvimento social. As análises sustentam-se em autores como Caldart (2008), Molina, Kolling e Nery (1999), Arroyo (2007), Marx (2001). Os resultados apontam um movimento inicial de constituição de uma concepção de educação do campo que extrapola a escola, caracterizada por especificidade local, reconhecimento da diversidade de saberes e relação entre trabalho e educação, movimento a ser fortalecido em um projeto coletivo que vislumbre a transformação da educação e a emancipação dos trabalhadores do campo.

PALAVRAS-CHAVE: Educação do campo, Desenvolvimento social do campo, Trabalho e educação.

\begin{abstract}
This work presents the analysis of a current rural education constitution on rural settlements, from a extension project combined with research that aims find actions and challenges, conceptions and perspectives about education, exposed to the field people, expliciting the tie-in between a educative project and a social development project. The analysis sustains on authors like Caldart (2008), Molina, Kolling and Nery (1999), Arroyo (2007), Marx (2001). The results point to the first steps of a current rural education conception that extrapolate the school, characterized for local specifities, recognizing the diversity of knowledge and the relationship between work and education, movement to be strengthened in a collective project that sees the education transformation and the emancipation of rural workers.
\end{abstract}

KEYWORDS: Current rural education, Social development of field, Work and education. 


\section{Introdução}

A discussão sobre educação do campo no Brasil remonta ao final dos anos 90, e as Diretrizes Nacionais da Educação Básica do Campo só foram aprovadas em 2002, pautadas na compreensão de que esta educação consiste em uma educação pensada a partir do contexto socioeconômico e cultural dos sujeitos do campo pertencentes à classe trabalhadora, que possui um projeto de sociedade antagônico ao projeto capitalista e, por isso, postula uma educação/escola capaz de promover a formação humana e crítica, numa dimensão que busca articular o desenvolvimento pessoal com o desenvolvimento social e econômico do campo.

Em 2003, o Conselho Estadual de Educação de Mato Grosso aprovou a Resolução 126, estabelecendo Diretrizes Operacionais das Escolas do Campo sob sua jurisdição; entre 2004 e 2006 foi realizado o primeiro seminário estadual e o primeiro seminário nacional de educação do campo e instituiu-se a Gerência Regional de Educação do Campo, bem como o Comitê Interinstitucional de Educação do Campo; em 2013, o Conselho Estadual aprovou a Resolução n. 03, que dispõe sobre a oferta da educação do campo em âmbito estadual. Tais ações caracterizam as iniciativas do poder público estadual, grande parte delas articuladas com as demandas dos movimentos sociais do campo.

Contudo, cabe questionar: em que medida tais ações chegam às escolas, considerando-se que muitas delas vinculam-se diretamente às secretarias municipais de educação e não à Secretaria de Estado de Educação? Qual é o entendimento que essas escolas/comunidades possuem sobre educação do campo e que perspectivas vislumbram para ela?

Visando compreender melhor as relações entre educação do campo e desenvolvimento comunitário, desenvolvemos um projeto de extensão em interface com pesquisa $^{1}$ em quatro assentamentos próximos a Cáceres/MT, com participação de educadores, pais/comunidade e jovens estudantes em oficinas e seminários. O presente artigo se refere a dados colhidos em dois destes assentamentos: Nova Conquista (38 sujeitos) e Roseli Nunes (28 sujeitos).

A metodologia de pesquisa Participante, incluindo seminário de diagnóstico, oficinas e seminários propositivos, se constituiu de uma dinâmica de reflexão sobre o que os sujeitos pensam, fazem e projetam para a educação do campo, sendo um valioso instrumento de reflexão das práticas e de reelaboração de projetos de educação do campo. Neste artigo, analisamos dados coletados em uma das fases do projeto, quando os membros da comunidade foram convidados a responder um questionário, cujos resultados foram sistematizados pelos pesquisadores e depois apresentados para discussão em nova reunião com a comunidade.

Para análise dos dados, as respostas foram agrupadas e classificadas pela proximidade entre elas. Quanto à questão inicial (o que pensam), na primeira classe, denominada "educação pertinente", foram reunidas as respostas que se referiam à educação do campo como aquela voltada à realidade do campo; em "educação crítico propositiva”, estão aquelas que apresentam a percepção de que é preciso mudar para 
melhorar; "educação inadequada" reúne as respostas que apenas indicam que a educação não está boa e são consideradas "indefinidas" respostas que não contém definições ou argumentos. Em relação a "o que fazem", a primeira classe de respostas, "educação tradicional" refere-se às ações meramente individuais, ainda que propondo ou citando mudanças; a segunda, denominada "ação inicial", agrupa as respostas que indicam inicio de mobilização e organização coletiva e a terceira, "educação expectativa", contém as que apenas manifestam desejos de mudanças. Quanto à terceira classe, "escola adequada", refere-se a respostas que indicam necessidades de mudanças infraestrururais; "desenvolvimento cognitivo" contém as respostas que indicam preocupação com ensino aprendizagem relacionadas ao desenvolvimento comunitário; e "desenvolvimento do campo" contempla as respostas que relacionam a educação do campo à questões mais amplas de desenvolvimento nas diversas áreas.

A partir dessas três questões respondidas pelos participantes, temos o objetivo de analisar, neste artigo, a constituição da educação do campo nas comunidades em foco, identificando concepções em que se pautam, ações e desafios que se colocam e perspectivas que têm.

\section{Escola Paulo Freire, Assentamento Nova Conquista}

O Assentamento Nova Conquista foi fundado em 1996 por força do Movimento dos Trabalhadores Rurais Sem Terra; é composto por cerca de 350 famílias e ocupa uma extensão de cerca de $40 \mathrm{~km}$; conta com duas escolas: Limoeiro e Paulo Freire; sua economia está sustentada na agricultura familiar e predominantemente na criação de gado para venda de leite a um laticínio da região.

Gráfico 1: O que sabe/pensa sobre educação do campo

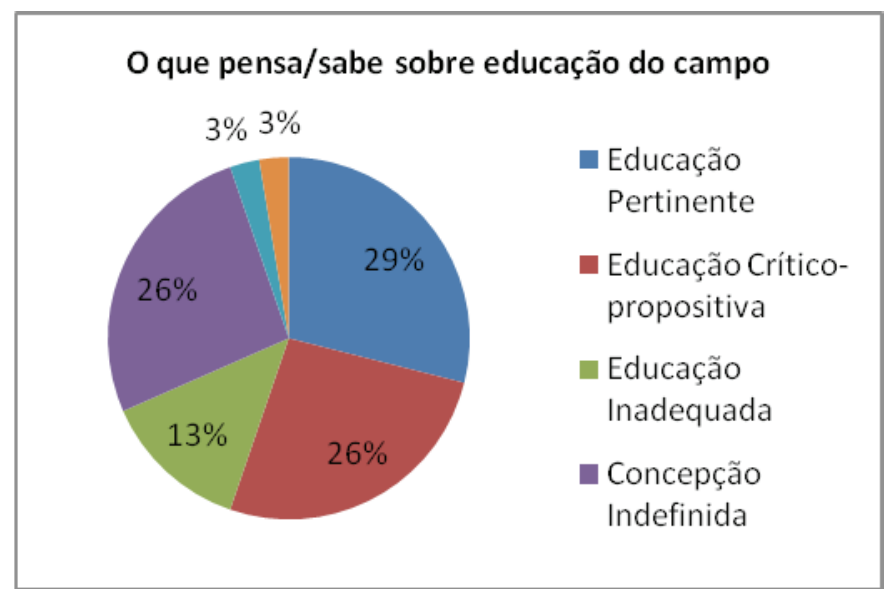

Fonte: Relatório do Projeto de extensão e pesquisa Educação e desenvolvimento comunitário, 2011.

O gráfico 1 mostra que 29\% dos respondentes afirmam a educação do campo como aquela que classificamos como pertinente e $26 \%$ destacam o que definimos como caráter crítico propositivo. Se tomarmos conjuntamente os dados, veremos então 
que $55 \%$ concebem a educação do campo como correspondente às expectativas das pessoas do campo, uma educação apropriada àquela realidade.

Uma educação voltada para cada realidade dos educandos e dos educadores.

Sei que a educação é uma proposta que está em construção, está sendo estudada, pensada de maneira a atender a diversidade cultural e social do campo, como também questöes de infraestrutura, principalmente, em assentamentos deixados ao acaso pelas autoridades. Penso que a efetivação dessa proposta depende da contínua luta dos movimentos sociais, das universidades, das politicas públicas e do empenho dos governantes.

É uma educação boa, mas estamos correndo atrás de uma educação melhor no campo, para que todos que estudem fiquem na comunidade após o ensino médio.

Que nosso filho aprenda ou preserve a natureza para o bem de todos seres vivos.

Dos participantes $26 \%$ não têm uma concepção definida a respeito do que é educação do campo, 3\% não responderam - provavelmente por não saberem, e 3\% afirmaram não saber; somando-se esses três índices, chegamos a 32\% de sujeitos que não possuem uma ideia clara de educação do campo. $13 \%$ entendem que essa educação não vai bem, embora não tenham precisado em que aspectos necessitaria melhorar. Provavelmente, a rotatividade grande, tanto em termos de estudantes quanto de educadores, nesta escola/assentamento, colabore para que o entendimento sobre educação do campo seja dificultado, uma vez que não se trata de simples troca de terminologia, mas de toda uma concepção educativa, implicada em um novo projeto de vida e sociedade, o que exige discussões aprofundadas e contínuas.

A educação do campo enquanto tal, isto é, com o devido reconhecimento legal de suas especificidades, vem sendo implementada desde o início do ano 2000, cabendo questionar a respeito do que tem sido realmente feito. Partindo do pressuposto de que a educação depende de uma ação coletiva e de que se estende para além "dos muros" da escola, perguntou-se aos participantes do Projeto: o que fazem em termos de educação do campo?

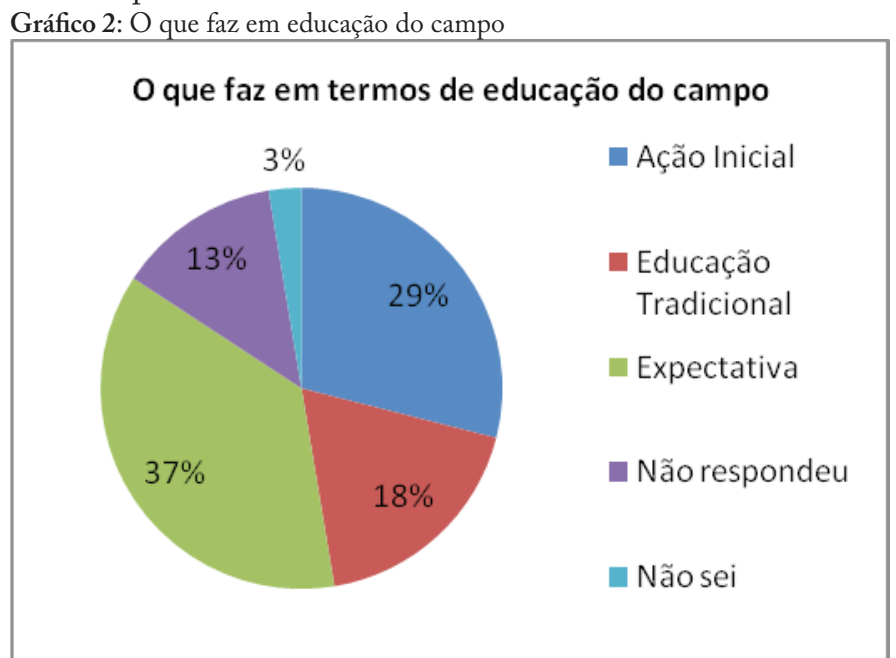

Fonte: Relatório do Projeto de extensão e pesquisa Educação e desenvolvimento comunitário, 2011. 
Podemos constatar que $28 \%$ dos participantes apontam para a realização de açôes iniciais no tocante à educação do campo, caracterizadas como sendo aquelas que reconhecem que já começaram a estudar a proposta de educação do campo, participam da mobilização dos movimentos sociais, realizam incipientes práticas educacionais novas, há um começo de iniciativas e da organização coletiva de um projeto de educação do campo. 36,84\% apresentam uma expectativa de que essa educação possa deslanchar, classe que manifesta uma situação individual em que se constatam problemas e desejos de superação.

Quase nada. Só participo da reunião voltada à sobrevivência.

Estou participando, pretendo participar até o final, para conhecer melhor a educação no campo e ter mais conbecimento.

Um pouco mais otimistas, $28,94 \%$ entendem que já existe uma ação inicial no sentido da concretização de uma proposta, principia-se um processo de organização coletiva em prol de um projeto de educação do campo.

Ainda estamos fazendo pouco, mas já comę̧amos a discutir e está num bom começo.

Estudando, conhecendo através de participação em encontros e transmitindo para a comunidade escolar o que consegui aprender.

No contraponto dessas posições, $18,42 \%$ consideram que a educação desenvolvida no assentamento/escola ainda é o que foi agrupado na classe tradicional, centrada na busca de melhoria do ensino (metodologias, mudança de calendário escolar, consideração à realidade do aluno), porém, sem dimensionar mudanças políticas e sociais mais amplas (projeto de desenvolvimento do campo).

Faz-se o melhor para que o aluno possa ter uma melhor aprendizagem na educação do campo.

Eu tento educar, cuidar conforme a realidade deles.

Flexibilidade no horário, cooperação e mobilização.

Não identificamos manifestações a respeito de mudanças ou de propostas coletivas. As respostas agrupadas nesta classe indicam a ideia de se fazer uma educação de qualidade, ao que parece, no sentido de equiparar-se à educação em qualquer outro lugar.

Nossos direitos e oportunidade de um estudo melhor no campo, de igual pra igual, para que todos tenham os mesmos direitos de educação. (grifo nosso).

Esses dados indicam a falta de um projeto coletivo de educação e de sociedade claramente articulado entre os respondentes, elemento fortemente defendido pelo MST, de cujas lutas e conquistas este assentamento e esta escola são frutos. As mudanças na constituição do assentamento, que perdeu a característica original de ser majoritariamente integrado por trabalhadores vinculados ao MST, provavelmente afetaram a organização social dos assentados, assim como a configuração de seu projeto 
político-educativo. A compra/venda de lotes descaracteriza o sentimento de pertencimento a um coletivo que luta por transformações mais amplas, que visam romper com a lógica da sociedade capitalista e instaurar uma sociedade igualitária e emancipatória. $\mathrm{Na}$ acepção marxiana, a verdadeira emancipação implica na socialização dos meios de produção e dos produtos entre os trabalhadores, eliminando-se a exploração de uma pessoa sobre a outra (MARX, 2001). Contudo, cabe destacar que há um desejo de mudar essa realidade.

As respostas indicam que ainda há muito que se trabalhar em função da consistência do grupo como um coletivo, sentindo-se responsável pela educação do campo, para que se avance, de ações educativas individuais e incipientes, para mudanças mais profundas.

\section{Quais as perspectivas para a educação do campo?}

Mais importante do que pensar na relação ou na distância entre o que os sujeitos pensam e o que fazem em termos de educação do campo, é pensar nas perspectivas de consolidação dessa educação no assentamento.

Gráfico 3: O que deseja/ projeta para a educação do campo

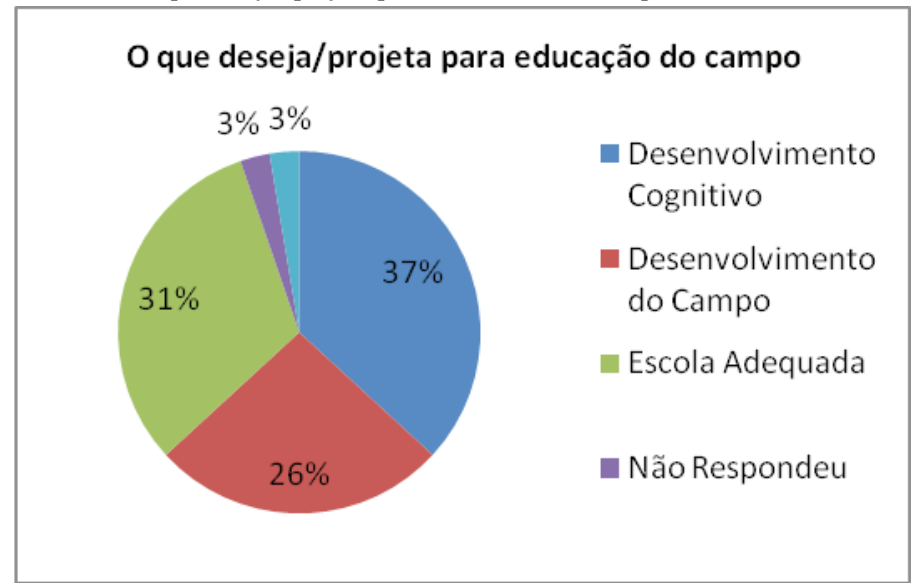

Fonte: Relatório do Projeto de extensão e pesquisa Educação e desenvolvimento comunitário, 2011.

Observa-se que a classe denominada desenvolvimento cognitivo, obteve $36 \%$ das respostas e pode ser entendida como: melhorar as metodologias de ensino, oferecer oportunidades, novas habilidades, aprendizados para o desenvolvimento da comunidade, troca e interação de saberes, intercâmbio de experiências. Essa questão vai ao encontro das discussões feitas pelos movimentos sociais do campo quando da proposição das diretrizes nacionais para a educação do campo. Os sujeitos do campo se contrapõem à posição a que historicamente foram condicionados, de que para eles bastam umas pinceladas de conhecimento; reivindicam o acesso ao saber científico.

Dos participantes 32\% desejam o que foi classificado como uma escola adequada, classe a qual inclui aspectos físicos e de pessoal da escola, professores capazes, infraestrutura da escola, tecnologias de comunicação, biblioteca, salas de vídeo, 
alimentação e transporte escolar, carteiras, currículo, continuidade dos estudos. $26 \%$ projetam também o que se denominou desenvolvimento do campo, compreendendo: infraestrutura do campo (estradas, transporte, posto de saúde), oportunidades de trabalho e renda, meio ambiente (manejo), direitos socioeconômicos e culturais, políticas públicas para a permanência no campo.

As respostas obtidas indicam que, ao pensar e projetar educação do campo, apenas $26 \%$ dos participantes da pesquisa, nessa comunidade, vinculam educação do campo às demais questões que compõem um projeto de campo, ou seja, compreendem a educação como um componente do desenvolvimento comunitário, ao indicar a necessidade de políticas públicas para o campo como forma de garantia de infraestrutura econômica local e de outros direitos dos sujeitos do campo.

\section{Escola Madre Cristina, Assentamento Roseli Nunes}

O Assentamento Roseli Nunes foi constituído pela mobilização do MST, no ano de 2002; situa-se no município de Mirassol D’Oeste/MT e abriga mais de 400 famílias; possui uma escola que atende da educação infantil ao ensino médio, numa articulação entre as redes municipal e estadual de ensino. A economia predominante neste assentamento é a agricultura familiar, com a plantação de verduras e hortaliças, comercializadas junto à $\mathrm{CONAB}$ e para abastecimento de escolas da região - trabalho articulado via cooperativa de trabalhadores locais.

Mais da metade das respostas dos participantes da pesquisa pode ser agrupada na ideia de uma educação pertinente, isto é, que viria ao encontro dos anseios dos sujeitos do campo, em termos de formação escolar específica e de qualidade e, também, de desenvolvimento local.

Gráfico 4: O que sabe/pensa sobre educação do campo

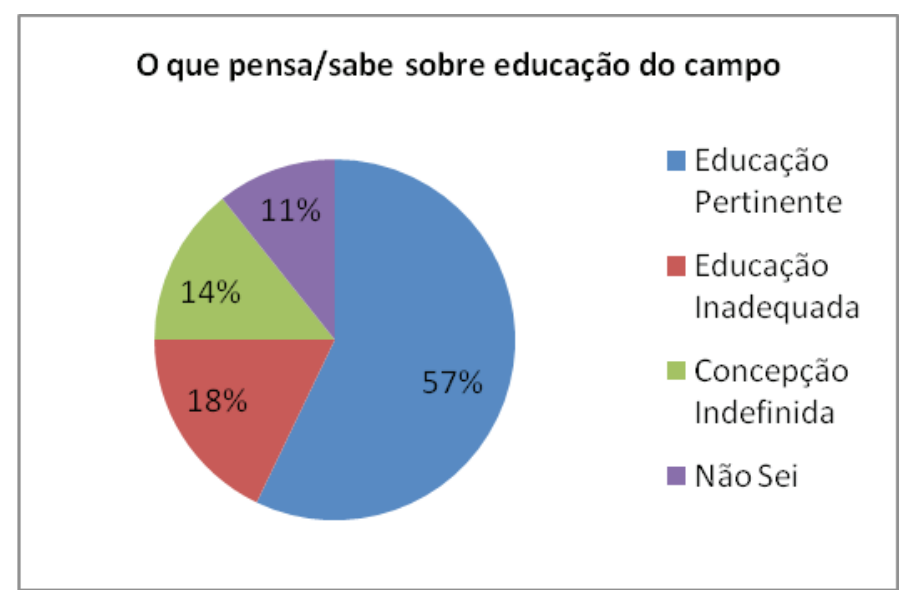

Fonte: Relatório do Projeto de extensão e pesquisa Educação e desenvolvimento comunitário, 2011.

Um dos aspectos mais ressaltados pelos respondentes foi a questão da cultura; usaram palavras como conhecimento, saberes, aprendizagens e costumes. A ideia de 
valor e valorização apareceu 14 vezes nas respostas, ao manifestarem sua compreensão de educação como um processo que cria, reforça, ensina ou trabalha com valores e que estes, por sua vez, estão ligados a uma cultura, no caso, à cultura camponesa.

A educaşão do campo é a valorização do sujeito do campo, valorizando todos os seus conhecimentos que foi acumulado com o passar do tempo.

É o respeito à cultura, às diversidades do local, à valorização dos saberes antigos $e$ inclusão de novos saberes.

Educação do campo não é só na escola, mas também, sobretudo que o camponês tem que exercer no campo, é uma educação voltada para a realidade dos camponeses, que valorizem suas ideias, cultura e sua identidade.

Nessas falas fica evidenciado o entendimento de que educação não se faz apenas nos espaços escolares e, quando se refere especificamente à escola, precisa levar em conta ideias, cultura e identidade camponesas, conforme abordado por Molina, Kolling e Nery (1999), Arroyo (2007) e pelas Diretrizes Nacionais da Educação do Campo.

As respostas classificadas como educação pertinente fazem, muitas vezes, referências à diversidade, ou seja, à compreensão da singularidade dos sujeitos, dos saberes de cada um e das diferenças locais, mesmo que, nos processos educativos, estejam em relação com novos ou outros conhecimentos.

\section{A educação do campo é uma educação libertadora que respeita a singularidade do educando e explora seu saber por simples que seja. \\ É o respeito à cultura, às diversidades do local, à valorização dos saberes antigos e inclusão de novos saberes.}

As ideias de educação inadequada e de resposta indefinida se referem a respostas de pessoas que apenas emitiram um juízo de valor sobre a educação do campo, dizendo que é uma coisa boa, mas não disseram como a entendem. Se somadas estas duas classe aos $11 \%$ que responderam "não sei", teremos quase $40 \%$ que não compreendem claramente o que é a educação do campo.

Independente de expressarem uma concepção "ideal” acerca do que seja, os participantes do Projeto são membros da comunidade e, portanto, estão envolvidos com a educação que ali se desenvolve. Assim, quando inquiridos a respeito do que fazem em relação à educação do campo, posicionam-se entre estar iniciando algumas ações e possuir expectativas a respeito. 
Gráfico 5: O que faz em educação do campo

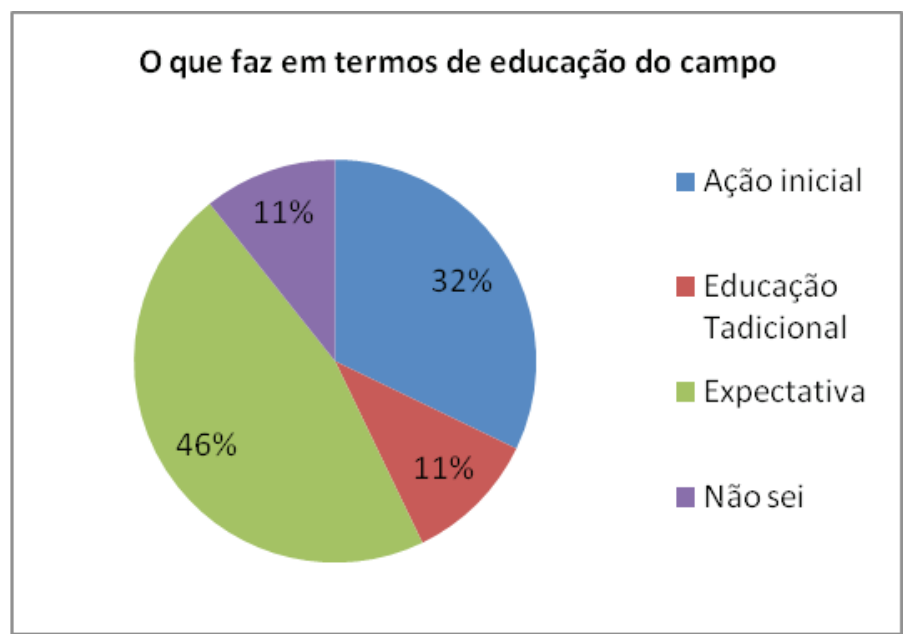

Fonte: Relatório do Projeto de extensão e pesquisa Educação e desenvolvimento comunitário, 2011.

Aproximadamente um terço das pessoas que responderam se encaixam na ideia de estar realizando uma ação inicial, isto é, pensando e realizando ações que favorecem sua concretização. A frase a seguir é bem ilustrativa, pois se refere a ações no campo das lutas sociais, mas que têm um caráter educativo, que "preparam o terreno" para a proposição e realização de uma educação escolar do campo:

Acho que a luta que fazemos através do MST para combater a desigualdade social, a discriminação e lutas por nossos direitos para que possamos ser sujeitos da nossa própria bistoria. Isso é um esforço nesse sentido.

[...] sendo sujeitos em propor caminhos dentro de um resgate bistórico que nos fortalece nas misticas e nos projetos de vida.

A ideia de historicidade se faz presente: são ações que ao mesmo tempo resgatam - no sentido de algo que já se teve e está submerso ou perdido, mas que tem como horizonte um futuro - um projeto de vida. Esta ideia insere-se na perspectiva de educação do campo e de escola do campo, que vem sendo discutida no contexto das lutas dos movimentos sociais do campo, em âmbito nacional.

[...] a escola do campo, como parte de um projeto maior da classe trabalhadora, se propõe a construir uma prática educativa que efetivamente fortaleça os camponeses para as lutas principais, no bojo da constituição histórica dos movimentos de resistência à expansão capitalista em seus territórios. (MOLINA; SÁ, 2011, p. 326).

Três outras palavras presentes nas respostas sobre o que se faz em educação do campo chamam atenção porque indicam as condições em que se faz: luta, coletivo e identidade. Elas nos indicam como se faz educação do campo. 
Não sair do campo já é uma forma de se educar, não negar a identidade de camponês.

A educação do campo não é uma ação individual e só e possível se for uma ação coletiva.

As lutas que travamos no nosso movimento MST.

Os textos legais e a literatura sobre esse tema corroboram o pensamento de que, na construção da educação do campo, destaca-se a participação ativa de educadores, pais e educandos no espaço escolar nas discussões sobre políticas públicas, sobre o Projeto Político Pedagógico, sobre conhecimentos científicos e cultura dos povos do campo.

Os $11 \%$ que aparecem no gráfico como educação tradicional se referem a quando o educador se esforça para melhorar o ensino, leva em conta a realidade do aluno, propõe novas metodologias de ensino, fala de mudanças no currículo e no calendário, mas é um esforço individual/pessoal, limitado a questões mais técnico-metodológicas.

Essa classificação nos leva a questionar: o que é possível fazer para que essas pessoas venham a compreender que as mudanças são processos necessários e coletivos e que precisamos uns dos outros?

O mesmo ocorre com os $40 \%$ que têm uma expectativa de ação em relação à educação do campo: manifestam uma situação em que se constatam problemas e desejos de superação, querem agir, mas de forma individual. São respostas como:

\section{Ajudo onde posso.}

Tento ajudar alguém se precisa de mim.

Muitas das respostas que compõem esse grupo vêm de estudantes, que apresentam uma expectativa ainda de caráter individual com relação à educação do campo, mas não têm clareza sobre seu papel nesse processo, fato que nos leva a pensar sobre a necessidade de detectar ações possíveis para avançar da expectativa para a concretização.

Gráfico 6: O que deseja/projeta para educação do campo?

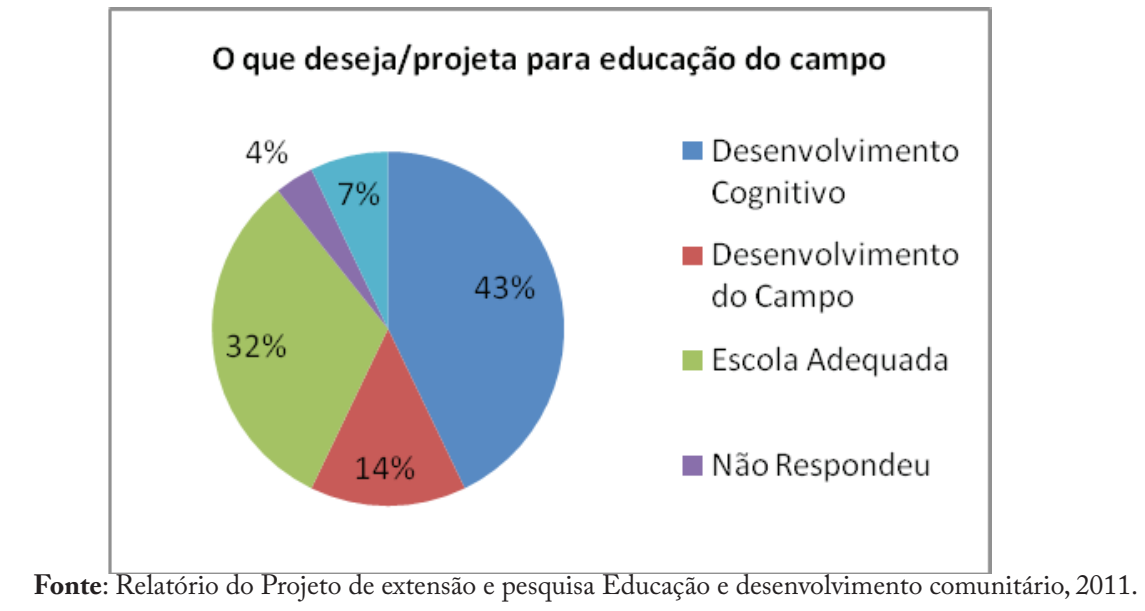


Um terço, aproximadamente, das pessoas que responderam a essa questão deseja uma escola que se pode chamar de adequada, que tenha as condições de efetivo funcionamento, desde materiais, humanas, até a sequência de estudos. Para alguns, isso seria parte do sentido de dizer uma educação de qualidade:

Que tenha mais qualidade no estudo, um desempenho melhor de alunos e professores.

Que tenha mais qualidade de ensino e estrutura escolar, alimentação mais saudável e professores mais conscientes com o tipo de educação que irão trabalhar.

Entre as respostas que foram classificadas, nos $43 \%$ denominados de desenvolvimento cognitivo, destacamos que há uma preocupação manifesta com o reconhecimento da educação do campo e sua especificidade:

Desejo que seja mais divulgada no meio que vivo e pelas autoridades competentes. (grifo nosso).

Desejo que não acabe o interesse de conhecimento sobre a educação do campo, pois é muito importante tanto para os educandos quanto para os educadores. (grifo nosso).

Desejo que essa educação seja pensada para a realidade do campo e que mais pessoas tenham acesso a esse conbecimento. (grifo nosso).

O reconhecimento pelo outro é parte constituinte do processo de identificação, é necessário que "os outros" nos reconheçam. A identidade se faz também pelo agrupamento em torno de semelhanças e pela marcação das diferenças; um processo de distinção entre o "nós" e os "outros".

A ideia de que os conhecimentos não estão presentes só na escola aparece neste grupo; propõe-se a troca entre a mistura, a união entre conhecimentos, saberes.

No grupo categorizado como desenvolvimento do campo, as ideias mais presentes são aquelas a respeito da necessidade de relacionar educação do campo com trabalho do/no campo:

[...] buscar mais alternativas de vida e trabalho onde o ser humano produza seu próprio sustento. (grifo nosso).

[...] uma política pública voltada para o campo e no campo [...]

[...] que seja fortalecida e com ênfase nos trabalhos e produção no campo. (grifo nosso).

E, apesar de manifesta uma única vez, há outra preocupação que se destaca:

[...] quando os educandos terminassem o ensino médio não saíssem daqui do assentamento, tivessem incentivos adequados para permanecerem aqui. 


\section{Desafios e Perspectivas da educação do campo}

Ao apresentarmos os dados desses assentamentos separadamente, temos a intenção de apreender o pensamento dos sujeitos a partir da especificidade de cada contexto, registrando a riqueza das falas e as contradições que as permeiam. Tomamos como pressuposto a relação dialética entre particular e universal (LÚKACS, 1981), consideramos pertinente tecer alguns comentários sobre o conjunto dos dados.

Quando instados a falarem o que sabem/pensam sobre educação do campo, a maioria dos sujeitos a situaram no âmbito de uma educaçâo pertinente, que valoriza os sujeitos do campo, leva em consideração os aspectos socioculturais dos assentados e contribui para que possam viver melhor nesse contexto. No caso do Assentamento Nova Conquista, $26 \%$ das respostas puderam ser classificadas como uma educação crítico-propositiva.

Por outro lado, as respostas "não sei", "não responderam" e "concepção indefinida" somam cerca de 40\% dos sujeitos do Assentamento Roseli Nunes e 32\% do Assentamento Nova Conquista, indicando um grande percentual de pessoas que não compreendem claramente o que é educação do campo, o que pode ser considerado certo entrave e, ao mesmo tempo, um desafio face aos objetivos de uma proposta de educação.

Embora 9\% dos sujeitos da Escola Madre Cristina e 28\% da Escola Paulo Freire digam que existem açôes iniciais em educação do campo, ainda é possível constatar que $36 \%$ e $46 \%$, respectivamente, expressam uma grande expectativa de que mudanças significativas ocorram. Um percentual maior no caso da primeira escola (18\%) e menor (11\%) no caso da segunda, entende que a educação que vem acontecendo é o que classificamos como tradicional - ainda não implicou em mudança na prática pedagógica e na formação, isto é, tentam fazer uma educação "de qualidade", mas não propõem nem relatam nenhuma mudança consistente.

No tocante à questão "o que desejam e projetam para a educação do campo", podemos observar certa similitude entre as respostas dos sujeitos das duas escolas em questão:

- em ambas as escolas, $32 \%$ disseram desejar uma escola que incluímos na classe denominada adequada, compreendendo as condições para seu efetivo funcionamento - estrutura física, equipamentos/materiais, possibilidade de sequência de estudos, professores habilitados, remetendo à concepção de uma educação de qualidade.

- a preocupação com o desenvolvimento cognitivo é aspecto enfatizado pela maioria dos sujeitos, 32\% na Escola Paulo Freire e 43\% na Escola Madre Cristina; desenvolvimento abordado tanto no sentido de que haja um reconhecimento maior das especificidades dessa educação quanto no sentido de que ela seja pensada a partir de e para a realidade do campo, considerando-se a importância de democratização de acesso, que cada vez mais um número maior de pessoas tenha acesso ao conhecimento. Mas qual co- 
nhecimento? De acordo com as falas dos sujeitos das duas escolas, trata-se de um conhecimento que não se limita à escola, mas abrange os saberes e fazeres que ocorrem no entorno, no assentamento. Neste sentido, propõe-se troca e articulação entre diversos tipos de conhecimentos como princípio inetrente ao processo de produção do conhecimento.

[...] Esta compreensão sobre a necessidade de um "diálogo de saberes" está em um plano bem mais complexo do que afirmar a valorização do saber popular, pelo menos na discussão simplificada que predomina em meios educacionais e que na escola se reduz por vezes a um artifício didático vazio. $\mathrm{O}$ que precisa ser aprofundado é a compreensão da teia de tensões envolvida na produção de diferentes saberes, nos paradigmas de produção do conhecimento. (CALDART, 2010, p. 112).

Nas falas dos participantes, transparece a preocupação com o trabalho, tanto como mecanismo articulador do desenvolvimento do campo, quanto da relação entre escola e comunidade, escola e vida no assentamento, configurando-se um entendimento da necessidade de vinculação entre educação e trabalho, no sentido de vivificar o conhecimento e produzir transformações na realidade na qual se vive, a partir da apreensão dessa realidade, das contradições que a permeiam e das mediações possíveis de serem realizadas com vistas à superação. Essa relação pauta-se numa concepção de trabalho como

[...] relação social fundamental que define o modo humano de existência, e que, enquanto tal, não se reduz à atividade de produção material para responder à reprodução físico-biológica (mundo da necessidade), mas envolve as dimensões sociais, estéticas, culturais, artísticas, de lazer, etc. (mundo da liberdade). (FRIGOTTO, 1989, p. 14).

A criação de mecanismos potencializadores do trabalho/produção no campo não é responsabilidade única da escola, mas algo que depende do estabelecimento de políticas públicas para o campo. Portanto, a relação trabalho-educação é um princípio basilar da educação do campo, que só pode ser entendida pela tríade: campo-políticas públicas-educação (CALDART, 2008). Nesse aspecto, ainda temos muito que avançar para que as proposições de conjunto da educação do campo se traduzam em ações concretas, que possam beneficiar diretamente a quem de direito: os trabalhadores e as trabalhadoras do campo.

Em síntese, é possível observar um movimento, no âmbito das ideias, em torno de uma educação do campo caracterizada pelo reconhecimento da especificidade local, da diversidade sociocultural e do conhecimento existente para além da escola e pela relação entre trabalho/educação; e um movimento apenas iniciado - ainda não concretizado - na organização e nas práticas pedagógicas escolares, com a força correspondente às expectativas da comunidade. Os dados indicam a compreensão dos sujeitos sobre quais as condições e relações necessárias e de qual conhecimento se trata quando se manifestam por uma educação do campo com qualidade. Há que se investir na "encarnação" dessas ideias por meio de práticas diferenciadas. 
O exercício constante de pensar coletivamente sobre questões relativas aos interesses e necessidades da comunidade é promissor, posto que fortalece laços de identidade e ressignifica concepções necessárias à transformação social, tais como educação do campo, trabalho, economia solidária, agroecologia e políticas públicas, e coloca em evidência o coletivo, tão necessário a uma proposta de transformação. Podemos dizer que está ocorrendo um movimento de articulação em torno da educação do campo, que vai além da formação escolar, estendendo-se rumo a uma ideia mais ampla de desenvolvimento, econômico e social.

\section{Referências}

ARROYO, M. G. Políticas de formação de educadores(as) do campo. Caderno Cedes, Campinas, v. 27, n. 72, p. 157-176, maio/ago. 2007.

CALDART, R. S. Sobre educação do campo. In: SANTOS, Clarice Ap. (Org.). Por uma educação do campo: campo, políticas públicas, educação. Brasília: Incra/MDA, 2008.

A Educação do Campo e a perspectiva de transformação da forma escolar. In: MUNARIM, A. et al. (Org.). Educação do Campo: reflexões e perspectivas. Florianópolis: Insular, 2010.

FRIGOTTO, G. Trabalho, conhecimento, conhecimento e a educação do trabalhador: impassesteóricos e práticos. In: GOMES, Carlos M. et al. (Org.) Trabalho e conhecimento: dilemas na educação do trabalhador. São Paulo: Cortez/Autores Associados, 1989.

LUCKÁCS, G. O trabalho: por uma ontologia do ser social (tradução de Ivo Tonet). Universidade Federal de Alagoas, 1981.

MARX, K. O capital: crítica da economia política. Livro I, v. I, 18. ed. Rio de Janeiro: Civilização Brasileira, 2001.

MOLINA, M.; KOLLING, E.; NERY, I. (Org.). Por uma educação básica do campo. Brasília: Editora da UnB, 1999.

MOLINA, M.; SÁ, L. M. Escola do Campo. In: Dicionário de educação do campo. CALDART, Roseli et. al. (Org.). São Paulo: Expressão Popular. Rio de Janeiro: Escola Politécnica Joaquim Venâncio, 2011.

\section{Nota}

${ }^{1}$ Projeto de Extensão/pesquisa "Educação e desenvolvimento comunitário", coordenado pelo Prof. Dr. Laudemir Luiz Zart, UNEMAT.

* Professora Doutora da Universidade do Estado de Mato Grosso, Caceres, Mato Grosso, Brasil.

** Professora Doutora da Universidade do Estado de Mato Grosso, Caceres, Mato Grosso, Brasil.

\section{Correspondência}

Heloisa Salles Gentil - Universidade do Estado de Mato Grosso, Faculdade de Educação. Av. São João S/N, Cavalhada. CEP: 78200-000 - Caceres, Mato Grosso, Brasil.

E-mail: logenti12@gmail.com - ilma.ferreiramachado@gmail.com

Recebido em 20 de junho de 2014

Aprovado em 01 de dezembro de 2014 